\title{
A simplified technique for pulmonary autograft stabilization with the Valsalva prosthesis
}

\author{
Joel Price, MD, MPH, ${ }^{\mathrm{a}}$ Saadallah Tamer, MD,${ }^{\mathrm{b}}$ Laurent de Kerchove, MD, ${ }^{\mathrm{b}}$ and Gebrine El Khoury, MD, ${ }^{\mathrm{b}}$ \\ Baltimore, Md, and Brussels, Belgium
}

Late failure of the Ross operation is frequently related to dilation and regurgitation of the pulmonary autograft. ${ }^{1,2}$ We have developed a technique for autograft implantation within a Valsalva prosthesis to prevent dilatation.

\section{SURGICAL TECHNIQUE}

A transverse aortotomy is performed, and the aortic valve is excised. A root dissection with creation of coronary buttons is then performed. The pulmonary trunk is divided. Once the pulmonary valve has been deemed acceptable, a point anteriorly at a level just below the nadir of the valve leaflets is punctured with an angled clamp. The valve is then dissected free circumferentially.

Once the autograft has been prepared, commissural height from the base of the interleaflet triangle to the apex of the commissure is measured. This corresponds to the diameter of the Valsalva graft to be selected. The inferior skirt of the Valsalva graft is removed. The autograft is placed inside the Valsalva graft and inverted. At the middle of the base of each interleaflet triangle, a single 4-0 polypropylene suture is placed through both autograft and Valsalva graft and tied externally (Figure 1, $A$ ). This ensures homogeneous suture placement, which is crucial to avoid distortion of the valve. A simple running suture is then performed circumferentially to complete the proximal anastomosis. Then, at the apex of each commissure, a 4-0 polypropylene suture is passed through the autograft and Dacron polyester fabric at the height of the neosinotubular junction of the Valsalva graft and tied externally (Figure 1, $B$ ). Once again, a simple running suture is then performed circumferentially to complete the distal anastomosis. At this point, the autograft is fixed proximally and distally within the prosthesis (Figure 1,C).

\footnotetext{
From the Division of Cardiac Surgery, ${ }^{a}$ Department of Surgery, the Johns Hopkins Hospital, Baltimore, Md; and the Department of Cardiovascular and Thoracic Surgery, ${ }^{\mathrm{b}}$ Cliniques Universitaires Saint-Luc, Université Catholique de Louvain, Brussels, Belgium.

Disclosures: Authors have nothing to disclose with regard to commercial support. Presented at Aortic Symposium 2012, New York, New York, April 26-27, 2012.

Received for publication June 18, 2013; revisions received Sept 9, 2013; accepted for publication Sept 17, 2013; available ahead of print Nov 1, 2013

Address for reprints: Joel Price, MD, MPH, Division of Cardiac Surgery, The Johns Hopkins Hospital, Sheikh Zayed Tower, Suite 7107, 1800 Orleans St, Baltimore, MD 21287 (E-mail: jprice@jhmi.edu).

J Thorac Cardiovasc Surg 2014;147:530-1

$0022-5223 / \$ 36.00$

Copyright (c) 2014 by The American Association for Thoracic Surgery

http://dx.doi.org/10.1016/j.jtcvs.2013.09.036
}

The proximal anastomosis of the autograft implantation is performed with 3 running 4-0 polypropylene sutures, 1 for each sinus (Figure 2, A). The graft is telescoped into place, and the sutures are tied. Next, appropriate locations are selected for the coronary buttons. A hole is created in the graft with ophthalmic cautery, then a hole is created in the autograft with scissors. Care is exercised to ensure both holes are of the same size and in the same location. The anastomosis is performed with a 5-0 polypropylene suture, carefully including the Dacron graft and pulmonary root tissue in the anastomosis (Figure 2, B). A pulmonary homograft is inserted into the right ventricular outflow tract. Finally, the distal aortic anastomosis is performed with a running 4-0 polypropylene suture. The final product yields a functioning autograft entirely fixed within the Valsalva prosthesis.

This technique was performed in 15 patients between 2005 and 2012, with no operative mortality. In our experience, this technique adds only modestly to operative duration. The mean cardiopulmonary bypass time was $162 \pm 19$ minutes, and the mean crossclamp time was $136 \pm 14$ minutes.

\section{DISCUSSION}

This technically straightforward approach has a number of potential advantages relative to previously described techniques. The autograft is fixed at all levels, not just the sinotubular junction and annulus. Unlike pericardium, Dacron polyester fabric has no potential to contract or calcify with time. Al Rashidi and colleagues ${ }^{3}$ have shown that reinforcement of the autograft prevents dilation as long as 4.5 years with a tube graft. We believe that the native shape of the neoaortic sinuses is preserved by the use of the Valsalva graft. This possibly contributes to more physiologic leaflet closure, improved durability, and better long-term function of the neoaortic valve. ${ }^{4}$ Also, unlike an oversized tube graft, the Valsalva graft simultaneously fixes the annulus and sinotubular junction at the chosen size while allowing for the increased diameter of the sinuses. Carrel and colleagues ${ }^{5}$ reported encouraging shortterm results with a Valsalva graft and a similar technique. Our technique differs from that described by Carrel and colleagues $^{5}$ in that we include the Valsalva graft in the coronary button anastomoses as a buttress. We create large holes and have never observed pseudoaneurysm formation. 

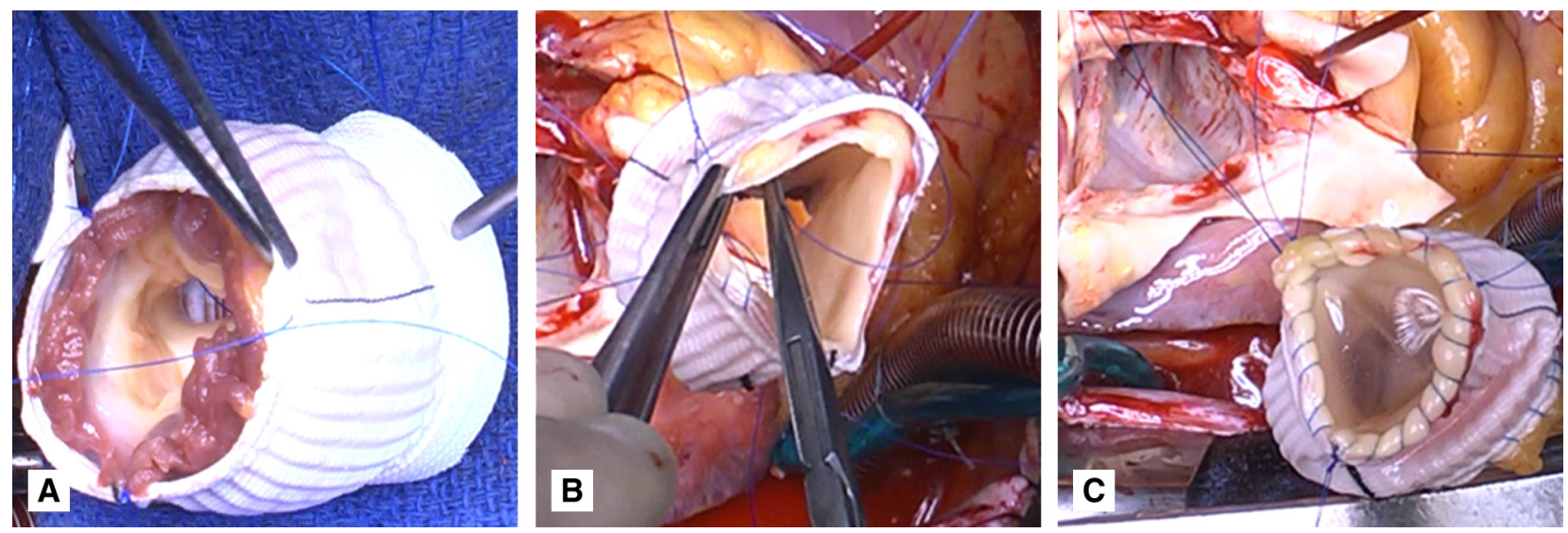

FIGURE 1. A, Each interleaflet triangle is fixed with a single 4-0 polypropylene suture tied externally. B, The apex of each commissure is fixed with a single 4-0 polypropylene suture tied externally. C, The autograft is fixed proximally and distally within the prosthesis.
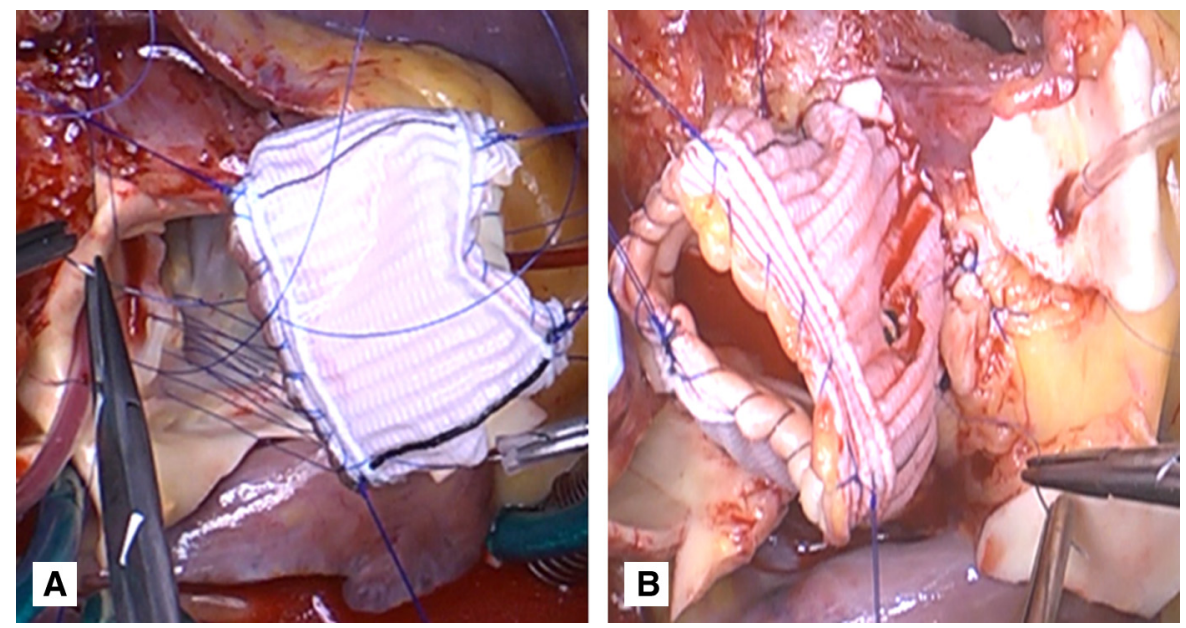

FIGURE 2. A, The proximal anastomosis of the autograft implantation is performed with 3 running 4-0 polypropylene sutures, 1 for each sinus. B, Coronary button anastomoses are performed with 5-0 polypropylene suture with the prosthesis and pulmonary root tissue included in the anastomosis.

Our technique for graft sizing greatly simplifies implantation. The construction of the Valsalva graft is such that the diameter of the tubular portion is equal to the height of the sinus portion. By using commissural height to select the graft size and then implanting the apices of the commissures at the level of the sinotubular junction of the Valsalva graft, we ensure that the valve is suspended at the correct height without the need for estimation.

The use of the Valsalva graft for our modification of the Ross procedure provides additional technical simplicity and potentially increased durability. We use this technique for patients with bicuspid aortic valves, dilation of the aortic root, or aortic insufficiency not amenable to valve repair.

\section{References}

1. David TE, Omran A, Ivanov J, Armstrong S, de Sa MP, Sonnenberg B, et al. Dilation of the pulmonary autograft after the Ross procedure. J Thorac Cardiovasc Surg. 2000;119:210-20.

2. de Kerchove L, Rubay J, Pasquet A, Poncelet A, Ovaert C, Pirotte M, et al. Ross operation in the adult: Long-term outcomes after root replacement and inclusion techniques. Ann Thorac Surg. 2009;87:95-102.

3. Al Rashidi F, Bhat M, Hoglund P, Meurling C, Roijer A, Koul B. The modified Ross operation using a Dacron prosthetic vascular jacket does prevent pulmonary autograft dilatation at 4.5-year follow-up. Eur J Cardiothorac Surg. 2010;37: 928-33

4. De Paulis R, De Matteis GM, Nardi P, Scaffa R, Buratta MM, Chiariello L. Opening and closing characteristics of the aortic valve after valve-sparing procedures using a new aortic root conduit. Ann Thorac Surg. 2001;72:487-94.

5. Carrel T, Schwerzmann M, Eckstein F, Aymard T, Kadner A. Preliminary results following reinforcement of the pulmonary autograft to prevent dilatation after the Ross procedure. J Thorac Cardiovasc Surg. 2008;136:472-5. 